\title{
Síndrome pulmonar e cardiovascular por Hantavirus: aspectos epidemiológicos, clínicos, do diagnóstico laboratorial e do tratamento
}

\author{
Hantavirus pulmonary and cardiovascular syndrome: epidemiology, clinical \\ presentation, laboratory diagnosis and management aspects
}

Luiz Tadeu M. Figueiredo', Gelse Mazzoni Campos ${ }^{1}$ e Fernando Bellissimo Rodrigues ${ }^{1}$

\begin{abstract}
Resumo A síndrome pulmonar e cardiovascular por Hantavirus (SPCVH), é doença emergente com descrição crescente de casos no Brasil. Neste trabalho, estudou-se 8 casos confirmados da doença. Todos apresentaram febre e dispnéia. Taquicardia, astenia, hipotensão e estertoração pulmonar ocorreram em 75 a $87,5 \%$ dos casos. Plaquetopenia e hipoxemia ocorreram em $100 \%$ dos casos, hemoconcentração, leucocitose com desvio à esquerda e elevação de uréia e creatinina séricas em 75 a $87,5 \%$. Assistência respiratória, hidratação endovenosa e utilização de aminas vasoativas foram as medidas utilizadas nos pacientes. Ressalta-se que $o$ suporte ventilatório e cardiovascular deve ser precocemente instituído, preferencialmente em unidades de terapia intensiva, com precauções universais e respiratórias de isolamento. Deve-se ter cuidados com infusão excessiva de líquidos para não agravar o edema pulmonar. A mortalidade observada, de $50 \%$, é elevada, deveu-se à gravidade da doença e ao comparecimento tardio para tratamento intensivo. Deve-se informar sobre a SPCVH aos profissionais de saúde, considerando que casos de SPCVH, provavelmente, vêm passando desapercebidos.
\end{abstract}

Palavras-chaves: Síndrome pulmonar e cardiovascular por Hantavirus. Hantavirose. Terapia intensiva.

\begin{abstract}
The Hantavirus pulmonary and cardiovascular syndrome (HPCVS) is an emerging disease in Brazil. In this study, eight confirmed cases of HPCVS were studied. All the patients presented fever and dyspnea as well as thrombocytopenia and hypoxemia. Tachycardia, malaise, hypotension and lung rales occurred in 75 to $87.5 \%$ of the cases. Hemoconcentration, blood cell count increased and immature neutrophils, and high levels of creatinine were observed in 75 to $87.5 \%$. Intravenous liquid infusion, the use of drugs for increasing systemic vascular resistance and inotropism, and mechanic ventilation were used for the patients. Mechanical ventilation and volume administration should be started precociously, preferable in intensive care units employing recommended universal and respiratory precautions. Careful volume administration should be limited if signs of pulmonary edema develop. Mortality (50\%) is high and probably related to the severity of the disease as well as to a delayed attending of the patients for intensive management. It is important to report hantaviruses and HPCVS to the Brazilian medical community considering that many cases could be undiagnosed.
\end{abstract}

Key-words: Hantavirus cardiopulmonary syndrome. Hantaviruses. Intensive care therapy.

Os Hantavirus são vírus RNA esféricos, envelopados, com diâmetro de 80 a 120nm, que possuem projeções glicoprotéicas na superfície e compreendem um gênero na família Bunyaviridae. Possuem um genoma de fita simples, polaridade negativa e trissegmentado. Estes 3 segmentos de RNA, conhecidos como grande (L), médio (M) e pequeno (S), codificam, respectivamente, a proteína RNA polimerase RNA dependente, as glicoproteínas G1 e G2 da superfície viral e a proteína $\mathrm{N}$ do nucleocapsídio ${ }^{18}$.

Os Hantavirus têm sua evolução em estrito relacionamento com a de seus animais-reservatório, os quais, no continente americano, são roedores silvestres pertencentes à ordem Rodentia, família Muridae e subfamília Sigmodontinae ${ }^{27}$. Os roedores mantêm infecção persistente e Hantavirus podem ser detectados

\footnotetext{
1. Divisão de Moléstias Infecciosas e Tropicais do Departamento de Clínica Médica da Faculdade de Medicina de Ribeirão Preto da Universidade de São Paulo, Ribeirão Preto, SP.

Endereço para correspondência: Dr. Luiz Tadeu M. Figueiredo. Depto de Clínica Médica/FMRP/USP. Av. Bandeirantes 3900, 14049-900 Ribeirão Preto, SP, Brasil.

Tel: 5516 602-3271, fax: 5516 633-6695.

e-mail: Itmfigue@fmrp.usp.br

Recebido para publicação em 30/5/2000.
} 
em diversos órgãos do animal, mesmo após meses da infecção ${ }^{8}{ }^{26}$. São conhecidas como hantaviroses 2 doenças humanas distintas, a febre hemorrágica com síndrome renal que ocorre na Ásia e Europa e a síndrome pulmonar e cardiovascular (SPCVH) que ocorre nas Américas. No continente americano, foram estudados vários Hantavirus associados à SPCVH desde a primeira detecção desta doença, em 1993, nos Estados Unidos. Os vírus Sin Nombre, New York, Bayou, El Moro Canyon, Blue River, Muleshoe, New York, Monongahela e Black Creek Canal foram encontrados na América do Norte, o vírus Rio Segundo na América Central e os vírus Andes, Rio Mamoré, Caño Delgadito, Oran, Laguna Negra, Lechiguanas, Pergamino e Maciel, na América do Sul, incluindo, também, o Juquitiba, único Hantavirus descrito no Brasil como causador de doença humana até o momento 12151719

Os casos conhecidos de SPCVH nas Américas somavam 229 até março de 1998, a maioria nos Estados Unidos, 179, na Argentina, 142, no Chile 44 e no Paraguai, $34^{17}$. Evidências da presença de Hantavirus no Brasil são observadas desde a década de 70 . Um Hantavirus foi isolado pela primeira e única vez no Brasil, no Pará, de um Rattus norvegicus, na década de $80^{14}$. Também, nesta época, demonstrou-se presença de anticorpos para o vírus Hantaan, prototipo do gênero Hantavirus, em soros de roedores urbanos de Belém, São Paulo e Recife $^{14}$. Como evidências de infecção humana por estes vírus, em uma série com 212 soros de pacientes da região Norte do Brasil com suspeita de leptospirose, encontrouse IgG para Hantaan em 8,4\% e IgM em 1,9\% ${ }^{9}$. Em São Paulo, 5 de 409 doentes internados em 1976 com diagnóstico clínico de leptospirose apresentavam IgM para Hantaan ${ }^{9}$.

Em 1993, entre novembro e dezembro, adoeceram 3 indivíduos moradores da área rural de Juquitiba, SP. Os doentes apresentaram febre, cefaléia, prostração, náuseas e vômitos. Dois pacientes evoluiram com insuficiência respiratória aguda e foram a óbito. $O$ diagnóstico sorológico destes casos confirmou infecção recente por Hantavirus, evidenciando o primeiro surto conhecido de SPCVH no Brasil ${ }^{102124}$. Desde então, até agosto de 1999, cerca de 20 casos da doença foram notificados e com uma mortalidade bastante elevada, acima de $70 \%$. Observou-se SPCVH nos Estados do Rio Grande do Sul, Minas Gerais e Mato Grosso. Entretanto, a maioria dos casos conhecidos de SPCVH brasileiros ocorreu no Estado de São Paulo. Entre 1993 e 1997, notificou-se um caso no Município de Franca e outro no de Araraquara ${ }^{4}$. Em abril de 1998, 2 casos de hantavirose, um cursando com SPCVH e outro com hemorragias, ocorreram no oeste do Estado de São Paulo, Municípios de Tupi Paulista e Nova Guataporanga. Também, observou-se um caso na Cidade de São Paulo, entretanto, suspeita-se que este último indivíduo, tenha se infectado no Município de Cotia. Em 1999, 1 caso fatal de SPCVH foi observado na Região da Alta Paulista, no Município de Lucélia e outro caso fatal ocorreu no de Botucatu. Na Região de Ribeirão Preto, em 1998 e 1999, ocorreu a maioria dos casos de SPCVH brasileiros e os mesmos são motivo deste trabalho.

Acredita-se que o mecanismo habitual de infecção humana nas hantaviroses relacione-se à inalação de aerossóis contendo excretas de roedores. Entretanto, em surto ocorrido na Região de Bariloche, sul da Argentina, em 1996, causado pelo vírus Andes, ocorreu transmissão interpessoal do vírus entre os pacientes com SPCVH ${ }^{25}$. Cinco pacientes eram médicos, alguns outros, funcionários de um hospital, sendo que, um médico e um familiar de paciente infectaram-se pelo contato com outros pacientes, fora da área, em Buenos Aires. A transmissão interpessoal do vírus, observada unicamente neste surto, teria ocorrido por contato direto, ou inalação de aerossóis e fomites contaminados ${ }^{1725}$.

No presente trabalho, descreve-se aspectos epidemiológicos, clínicos, laboratoriais e do tratamento de 8 casos de SPCVH ocorridos na região de Ribeirão Preto, visando a alertar e a orientar profissionais da área médica quanto a esta doença emergente e que começa a suscitar interesse como problema de saúde pública.

\section{MATERIAL E MÉTODOS}

Analisou-se aspectos epidemiológicos, a apresentação clínica, os achados laboratoriais e a evolução de 8 casos confirmados de SPCVH ocorridos na Região de Ribeirão Preto, entre março de 1998 e junho de 1999. Seis destes pacientes foram atendidos no Hospital das Clínicas da Faculdade de Medicina de Ribeirão Preto, Universidade de São Paulo (HCFMRP-USP). Quatro pacientes faleceram e estes casos fatais, incluindo 2 que não foram atendidos no HCFMRP-USP, foram necropsiados em serviço de verificação de óbitos ligado à FMRP-USP.

Ribeirão Preto possui aproximadamente 600.000 habitantes, localiza-se a $21^{\circ} 11^{\prime} \mathrm{S}, 47^{\circ} 49^{\prime} \mathrm{W}$, na região nordeste do Estado de São Paulo e é centro de uma região com aproximadamente 3.500 .000 habitantes. A região é montanhosa, com 400 a $1000 \mathrm{~m}$ de altitude e entremeada por vales. O clima é tropical quente e úmido, com inverno seco. A mais importante atividade rural de Ribeirão Preto, que levou nas últimas 4 décadas ao desmatamento quase total da região, é a agroindústria da cana-de-açúcar.

O diagnóstico de hantavirose nos pacientes estudados foi feito através de teste sorológico tipo ELISA, com detecção de anticorpos IgG e IgM específicos para a proteína $\mathrm{N}$ e a glicoproteína $\mathrm{G} 1$ do vírus Sin Nombre. Estes reagentes foram fornecidos pelo Centers for Disease Control dos Estados Unidos. Nos dois primeiros casos de SPCVH o teste diagnóstico foi efetuado no Instituto Adolfo Lutz de São Paulo e nos outros 6 casos o teste foi realizado na Unidade Multidepartamental de Pesquisa em Virologia da FMRPUSP $^{11}$. 


\section{RESULTADOS}

Conforme mostrado na Tabela 1, os pacientes com SPCVH eram, em sua maioria, do sexo masculino (7 homens e 1 mulher), tinham idades entre 13 e 55 anos, predominando os adultos jovens, entre 20 e 30 anos. Observa-se que $75 \%$ tinham contato com meio rural em sua atividade profissional e que a doença parece independer de classe socio-econômica já que 2 pacientes eram lavradores e outros 3, proprietários rurais. Também, todos os casos, com exceção de 1, ocorreram nos meses de maio e junho, em 1998 e 1999.

Como é mostrado na Figura 1, os principais sinais e sintomas apresentados pelos pacientes incluíam, em todos os casos, febre e dispnéia. Taquicardia, astenia, hipotensão e estertoração à ausculta pulmonar ocorreram em 75 a $87,5 \%$ dos casos. Cefaléia, cianose, vômitos e tosse seca apresentaram-se em 50 a 62,5\% dos pacientes. Mialgia,

\begin{tabular}{|c|c|c|c|c|c|c|}
\hline Paciente & Sexo & $\begin{array}{l}\text { Idade } \\
\text { (anos) }\end{array}$ & Profissão & Procedência & Ocasião & $\begin{array}{l}\text { Evolução } \\
\text { da doença }\end{array}$ \\
\hline JAS & $M$ & 55 & lavrador & Guariba & $5 / 98$ & óbito \\
\hline FVL & M & 38 & agricultor & Guariba & $5 / 98$ & óbito \\
\hline AGS & M & 54 & pintor & Ribeirão Preto & $11 / 98$ & óbito \\
\hline DLM & M & 26 & agricultor & Jardinópolis & $5 / 98$ & óbito \\
\hline DSS & M & 29 & motorista* & Pontal & $5 / 98$ & cura \\
\hline $\mathrm{CB}$ & $\mathrm{F}$ & 13 & estudante & Cajurú & $6 / 99$ & cura \\
\hline GSP & M & 21 & lavrador & Cássia dos Coqueiros & $6 / 99$ & cura \\
\hline AJM & M & 32 & agricultor & Cajurú & $6 / 99$ & cura \\
\hline
\end{tabular}

* Motorista trabalhando no transporte de cana-de-açúcar, em contato com o meio rural.

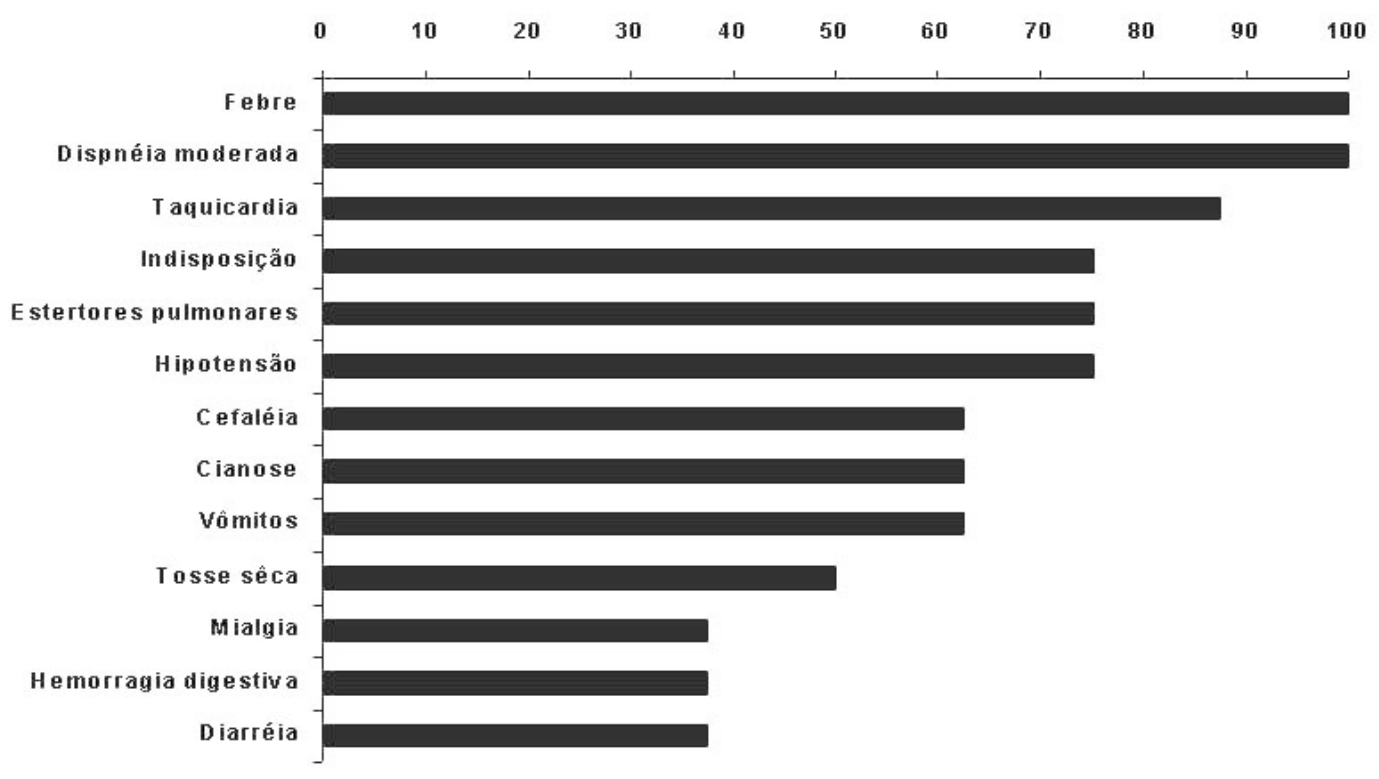

Figura 1 - Freqüência percentual de sinais e sintomas apresentados pelos oito pacientes com síndrome pulmonar e cardiovascular por Hantavirus.

diarréia e hemorragia digestiva foram menos comuns, tendo sido observadas em 1/3 dos pacientes.

Alterações encontradas em exames laboratoriais efetuados nos 8 casos estudados, à entrada no hospital, estão apresentadas na Figura 2. Observa-se plaquetopenia $\left(<150000 / \mathrm{mm}^{3}\right)$ e hipoxemia $\left(\mathrm{PO}_{2}<70 \mathrm{mmHg}\right)$ nos 7 pacientes em que o exame foi realizado. Hemoconcentração (hematócrito $>55 \%$ ), leucocitose $\left(>15000 / \mathrm{mm}^{3}\right)$, neutrofilia $\left(>7000 / \mathrm{mm}^{3}\right.$ ) com formas jovens (> 600 bastonetes $/ \mathrm{mm}^{3}$ ) e alterações de função renal (creatinina $>1,5 \mathrm{mg} / 100 \mathrm{ml}$ ), também, foram bastante freqüentes, ocorrendo em 75 a $87,5 \%$ dos casos. 
Um cronograma de aparecimento dos principais sinais, sintomas e alterações laboratoriais apresentados pelos pacientes encontra-se na Figura 3. Exames radiográficos de tórax mostrando a evolução da paciente CB são mostrados na Figura 4.

O organograma mostrado na Figura 5, pretende orientar o diagnóstico de casos suspeitos da hantavirose, considerando a fase da doença em que já existe acometimento pulmonar.

Aspectos importantes relacionados ao tratamento a que foram submetidos os 8 pacientes com SPCVH, são mostrados na Tabela 2.

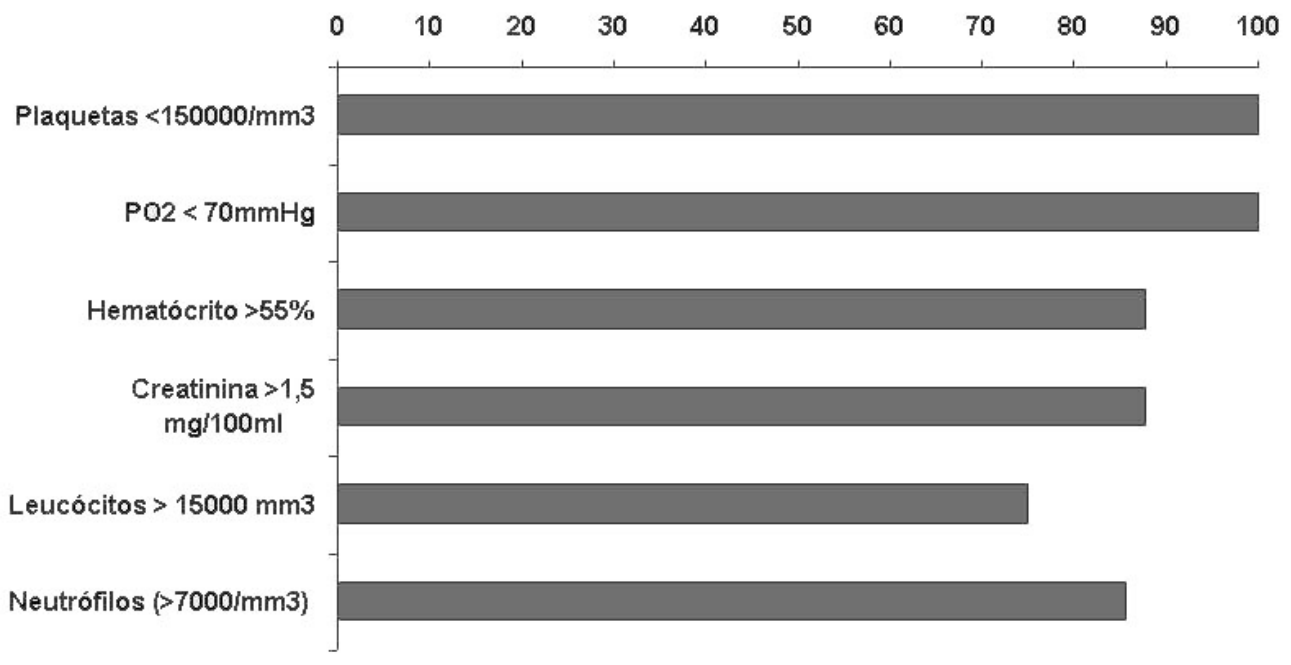

Figura 2 - Freqüência percentual de alterações em exames laboratoriais apresentados pelos oito pacientes com síndrome pulmonar e cardiovascular por Hantavirus.

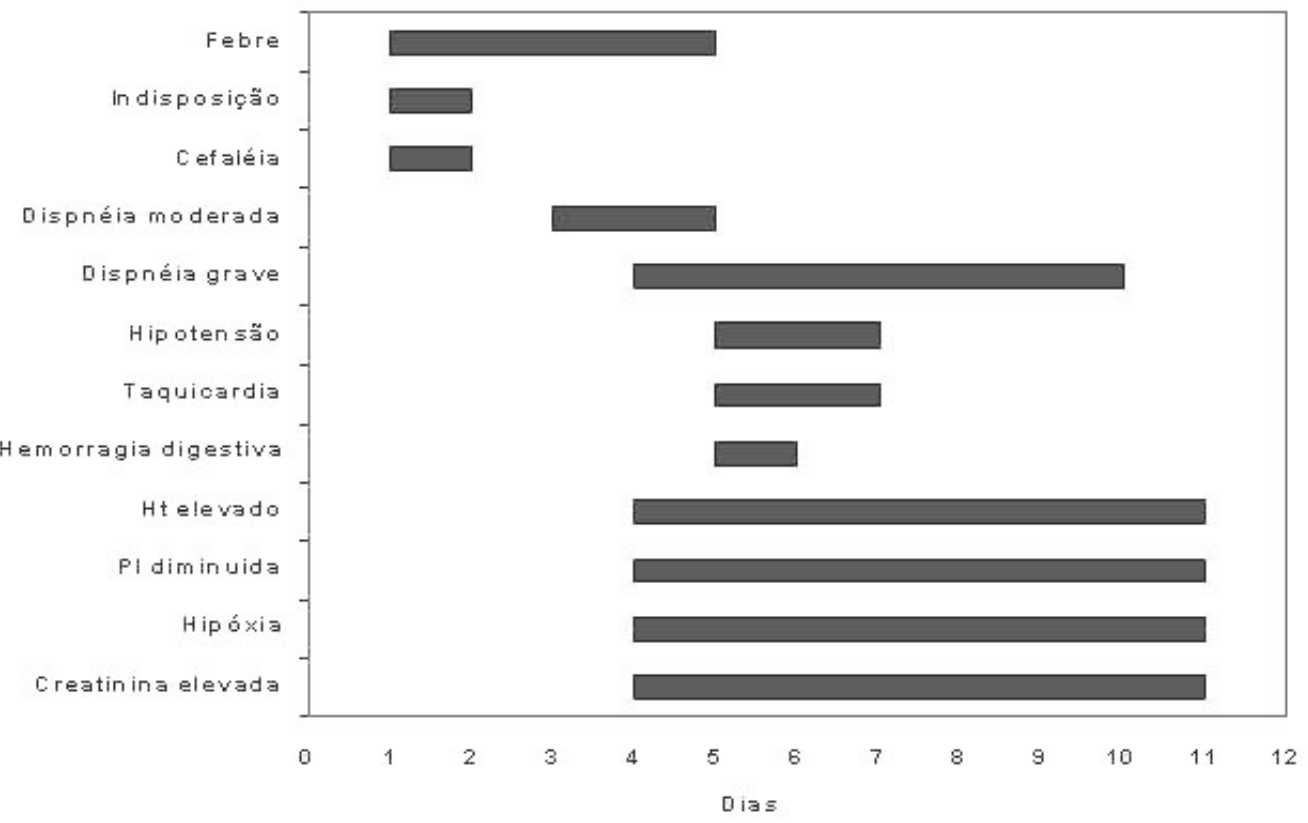

Figura 3 - Cronograma de aparecimento de sinais, sintomas e alterações laboratoriais apresentados pelos 8 pacientes com síndrome pulmonar e cardiovascular por Hantavirus. $H t=$ hematócrito; $P I=$ contagem de plaquetas no sangue. 


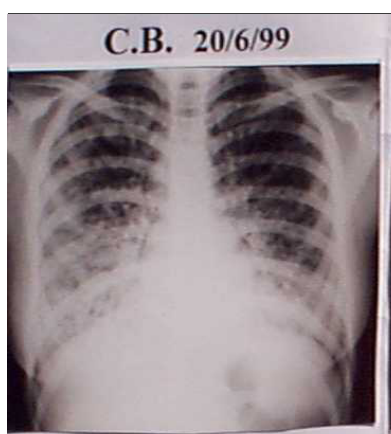

$27 / 6 / 99$
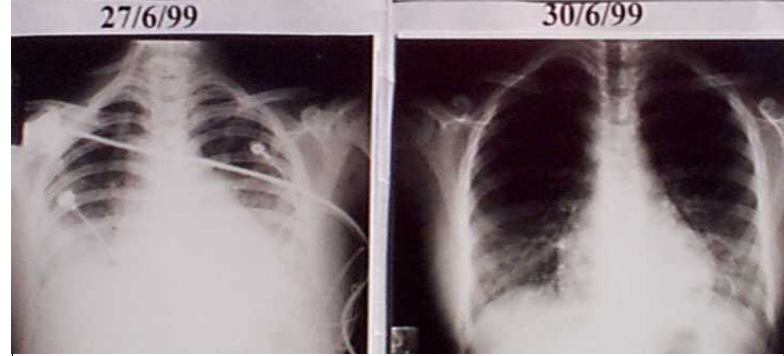

Figura 4 - Evolução radiológica da paciente C.B. com síndrome pulmonar e cardiovascular por Hantavirus: no exame de 20/6/99, observa-se velamento pulmonar de padrão misto, alveolar e intersticial, com áreas de confluência nas bases; no exame de inters/icial, com abserva-se aumento em extensão e densidade dos 22/6/99, observa-se aumento em extensao e densidade dos
velamentos que acometem completamente os pulmón: em 27/6/99, observa-se remissão progressiva dos infiltrados e que em 30/6/99 apresentam-se como reticulações apenas em bases pulmonares.

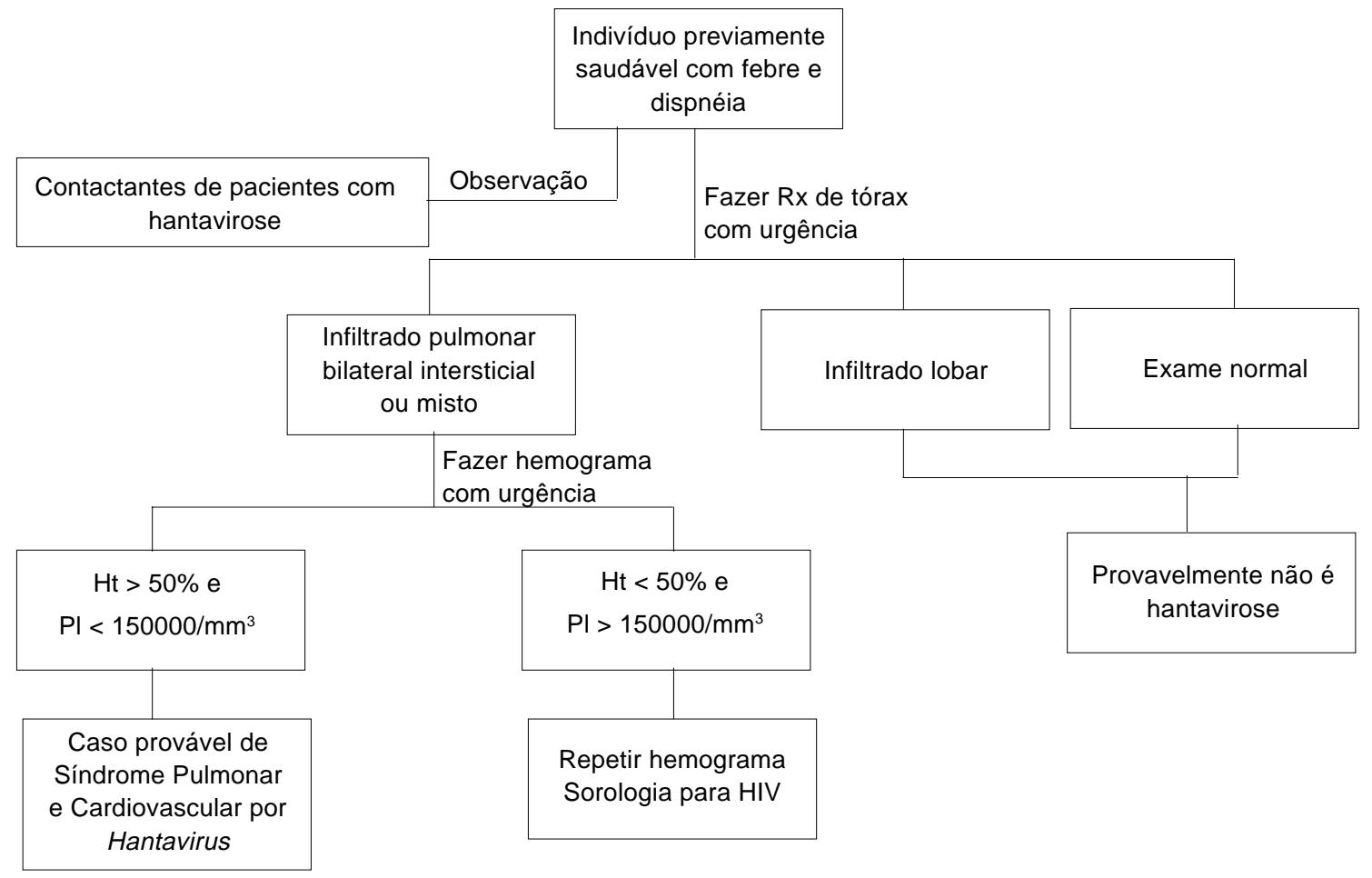

Figura 5 - Organograma para diagnóstico de um caso provável de síndrome pulmonar e cardiovascular por Hantavirus. $\mathrm{Ht}=$ Hematócrito; $\mathrm{Pl}$. = Contagem de plaquetas no sangue. 
Tabela 2 - Informações sobre o tratamento a que foram submetidos os oito pacientes com síndrome pulmonar e cardiovascular por Hantavirus.

\begin{tabular}{|c|c|c|c|c|c|c|c|c|}
\hline Paciente & JAS * & FVL & AGS $^{* *}$ & DLM & VSS & $\mathrm{CB}$ & GSP & AJM \\
\hline $\begin{array}{l}\text { Dia pós início dos sintomas } \\
\text { em que houve internação }\end{array}$ & 4 & 10 & 4 & 4 & 4 & 7 & 5 & 5 \\
\hline $\begin{array}{l}\text { Dia de internação em que se } \\
\text { fez diagnóstico clínico de } \\
\text { hantavirose }\end{array}$ & NFF & $1^{\circ}$ & 10 & ID & $2^{\circ}$ & 10 & 10 & 10 \\
\hline $\begin{array}{l}\text { Grau de hipóxia à internação } \\
\left(\text { Sat. } \mathrm{O}_{2}\right)\end{array}$ & $61 \%$ & $53 \%$ & $96 \%$ & ID & $71 \%$ & $72 \%$ & $82 \%$ & $73 \%$ \\
\hline $\begin{array}{l}\text { Presença de choque ou } \\
\text { hipotensão à internação }\end{array}$ & $S$ & $S$ & $\mathrm{~N}$ & S & $S$ & S & $S$ & N \\
\hline $\begin{array}{l}\text { Oxigenação pós internação: } \\
\text { dia de início }\end{array}$ & 10 & $2 \circ$ & 1 으 & 1 으 & 10 & 1 으 & 1 으 & 10 \\
\hline Tipo de oxigenação & VM & VM & VM & VM & VM & VM & VM & VMF \\
\hline $\begin{array}{l}\text { Dia de internação em que se } \\
\text { instalou PVC }\end{array}$ & $\mathrm{N}$ & 10 & 10 & N & 20 & 1 으 & 30 & N \\
\hline $\begin{array}{l}\text { Volume infundido nas } \\
\text { primeiras } 48 \mathrm{~h}\end{array}$ & $5,5 \mathrm{~L}$ & ID & $6 \mathrm{~L}$ & $3 L^{\prime \cdots}$ & $6,5 \mathrm{~L}$ & $4 \mathrm{~L}$ & $6 \mathrm{~L}$ & $2 \mathrm{~L}$ \\
\hline Uso de amina vasoativa & S & S & S & S & S & S & S & $\mathrm{N}$ \\
\hline Uso de corticosteróide & N & S & $S$ & N & N & N & $S$ & $S$ \\
\hline Antimicrobianos utilizados & PEN & $\begin{array}{l}\text { PEN } \\
\text { AMICA }\end{array}$ & CLO & $\begin{array}{l}\text { AZITRO } \\
\text { CEFTR } \\
\text { CLA }\end{array}$ & $\begin{array}{l}\text { COTRIM } \\
\text { CLA } \\
\text { GENTA }\end{array}$ & $\begin{array}{l}\text { CLO } \\
\text { CEFAL }\end{array}$ & $\begin{array}{l}\text { CLA } \\
\text { CLA }\end{array}$ & COTRIM \\
\hline Evolução & Óbito & Óbito & Óbito & Óbito & Cura & Cura & Cura & Cura \\
\hline
\end{tabular}

\section{DISCUSSÃO}

Embora considerando que se estudou uma casuística pequena, os dados apresentados sugerem uma sazonalidade para a SPCVH na Região de Ribeirão Preto. Sabe-se que na ocasião em que ocorreram $7 / 8$ dos casos, os meses de maio e junho, ou seja, em final do outono e início do inverno, ocorrem temperaturas médias de $19,4^{\circ} \mathrm{C}$ e $18,5^{\circ} \mathrm{C}$, as mais baixas do ano, e um índice pluviométrico médio baixo, de $40,2 \mathrm{~mm}^{3}$ em maio e $33,7 \mathrm{~mm}^{3} \mathrm{em}$ junho ${ }^{23}$. Essa época do ano, corresponde ao início da colheita da cana de acúcar, com abundantes queimadas de canaviais na Região. Curiosamente, nos Estados Unidos, apesar de viverem estações do ano opostas (primavera e verão), a maioria dos casos de
SPCVH, ocorreu nos meses de maio, junho e julho ${ }^{3}$. Sabe-se que distúrbios ecológicos favoreceriam surtos de SPCVH, como o causado pelo vírus Sin Nombre, nos Estados Unidos, em 1993. Naquele caso, houve chuva abundante com aparecimento de vegetação exuberante em região habitualmente desértica, a qual, servindo de alimento farto aos roedores silvestres, propiciou o surgimento de uma população excessivamente grande. Posteriormente, com o restabelecimento das condições climáticas habituais, a escassez alimentar levou os roedores a buscarem comida junto às casas rurais $e$ locais de armazenamento de cereais, o que facilitou a transmissão viral para os seres humanos ${ }^{16}$. Supondo- 
se que, atualmente, uma transmissão aumentada de Hantavirus para o homem possa estar a ocorrer na Região de Ribeirão Preto, hipóteses são formuladas visando explicar o fenômeno, tais como: nas últimas safras de cana de açúcar iniciou-se a mecanização da colheita, com redução das queimadas, o que poderia preservar os roedores criados nos canaviais e que anteriormente eram mortos, aumentando sua população; por outro lado, a redução das queimadas, determinada pela legislação, ocorre principalmente em plantações periurbanas, o que poderia facilitar com que roedores silvestres dos canaviais tenham começado a invadir a periferia das cidades em busca de alimentos; também, teria ocorrido, nos últimos anos, aumento na produção de cereais o que aumentaria a oferta de alimento para roedores silvestres e ainda, a pecuária na Região, com gado alimentado, cada vez mais, utilizando capim plantado e que produz muitas sementes, serviria de abundante alimento para os roedores silvestres e estimularia o aumento populacional destes animais. Entretanto, estas hipóteses além de sugerirem um procedimento antiecológico para controle das populações de roedores, a queimada dos canaviais, necessitam comprovação.

Na Região de Ribeirão Preto, em Guariba, estudo efetuado por Pereira ${ }^{16}$, em maio de 1998, observou uma altíssima densidade populacional de roedores silvestres no local em que se infectaram os pacientes JAS e FVL. $O$ autor atribui este achado à colheita manual do milharal, uma plantação antiga, circundada por canavial e mata de galeria e ao armazenamento deste milho no próprio campo, o que teria atraído ao local grande número de roedores. A pesquisa de anticorpos nos animais capturados sugeriu envolvimento das espécies silvestres Bolomys lasiurus (rato do rabo peludo), Akodon sp (rato da mata) e Oligoryzomys sp (ratinho do arroz) ${ }^{16}$.

Quanto ao local de contágio com Hantavirus dos outros pacientes deste estudo, CB, que mora em periferia urbana, referia a presença de roedores em sua casa, local onde, provavelmente, teria se infectado. O paciente GSP trabalhava no plantio de capim em local com abundantes roedores. O paciente VSS, motorista que trabalha no transporte de cana de açúcar, referia que no mês anterior à sua doença, um colega de trabalho, lavrador, teria falecido de pneumonia. Apesar de não confirmada a informação e a etiologia da doença fatal no caso citado, pode-se considerar a possibilidade de infecção no local de trabalho, o canavial.

Não foi possível precisar o período de incubação da SPCVH nos pacientes estudados. Entretanto, durante surto na Argentina o período de incubação foi determinado entre 11 e 29 dias $^{25}$. Os sinais e sintomas mostrados na Figura 1, bem como suas freqüências, são similares aos observados nos Estados Unidos durante o surto de SPCVH pelo vírus Sin Nombre. Neste surto de 1993, dispnéia ocorreu em $100 \%$ de 17 casos estudados, taquicardia em $94 \%$ e hipotensão em $50 \%{ }^{2}$. A hipotensão apresentada por $75 \%$ dos pacientes deste estudo, e observada na maioria dos pacientes com SPCVH, devese a uma redução do volume cardíaco de ejeção e do débito cardíaco embora ocorra acompanhada de uma elevação da resistência periférica ${ }^{22}$.

Ainda, com relação aos sintomas da SPCVH, mialgia foi observada em todos os pacientes no surto norteamericano e em apenas $1 / 3$ dos casos do presente estudo ${ }^{2}$. Também, a queixa de tonturas, freqüente em surtos norte-americanos e em um paciente de Juquitiba, não foi citada pelos pacientes do presente estudo ${ }^{17}$. Hemorragias, como a digestiva, observada em $1 / 3$ dos pacientes neste trabalho, são de descrição freqüente em surtos de SPCVH ocorridos na Argentina pelos vírus Andes e Lechiguanas ${ }^{17}$.

As alterações laboratoriais observadas no presente estudo são similares às de casos de SPCVH ocorridos nos Estados Unidos, onde se descreve uma tríade de alterações nos exames laboratoriais: trombocitopenia, leucocitose por neutrofilia com formas jovens (bastonetes, mielócitos e promielócitos) e imunoblastos e hemoconcentração ${ }^{22}$. Das alterações valorizadas pelos autores norte-americanos, não se observa no presente estudo imunoblastos circulantes, possivelmente devido à inexperiência dos examinadores em detectar estas células.

A insuficiência renal moderada, não necessitando hemodiálise, sugerida pela elevação da creatinina sérica em $87,5 \%$ dos pacientes do presente estudo, é pouco descrita nos surtos norte-americanos pelo vírus Sin Nombre embora tenha sido observada em quadros de SPCVH por outros Hantavírus norte-americanos como o Bayou e o Black Creek Canyon ${ }^{17}$. A hipoxemia, observada nos 8 pacientes estudados, mostra a gravidade da pneumopatia com insuficiência respiratória causada por esta hantavirose.

Analisando o cronograma da Figura 3, observa-se que a SPCVH se inicia com sinais e sintomas inespecíficos, febre, cefaléia e astenia. A dispnéia surge no $3^{\circ}$ ou $4^{\circ}$ dia de doença manifestando-se, inicialmente, aos moderados esforços, mas progredindo em 24 a 48 horas para dispnéia aos mínimos esforços, concomitante a uma inundação de alvéolos detectável por estertoragem crepitante disseminada ao exame dos pulmões. Também, acompanha a inundação de alvéolos pulmonares, tosse freqüente com eliminação de secreção pulmonar rósea. A dispnéia, desconfortável e incapacitante, é o que leva o paciente a procurar assistência médica, mais comumente no $4^{\circ}$ dia de doença. Na admissão hospitalar, que costuma ocorrer no $4^{\circ}$ ou $5^{\circ}$ dia de doença, já estão presentes a hipotensão, o hematócrito aumentado (> 55\%), a plaquetopenia $\left(<150.000 \mathrm{~mm}^{3}\right)$, a hipóxia $\left(\mathrm{PO}_{2}<70 \mathrm{mmHg}\right)$ e a creatininemia elevada $(>1,5 \mathrm{mg} / 100 \mathrm{ml})$. Nos pacientes que sobreviveram à doença, $50 \%$ dos casos, o curso clínico e laboratorial mostrou melhora acentuada das funções respiratória, renal e hemodinâmica em torno do $10^{\circ}$ dia após início dos sintomas, ou seja, após 5 ou 6 dias de 
internação. Simpson, $1998^{22}$, com base em casos ocorridos na América do Norte, descreve a SPCVH de forma similar à observada no presente estudo e ressalta a presença de 4 fases. A prodrômica, com duração de 3 a 6 dias, quando surgem abruptamente os sintomas respiratórios e o choque, caracteristicos da $2^{\text {a }}$ fase e que costumam perdurar por 3 a 6 dias. Pacientes que sobrevivem às primeiras 48 horas da fase respiratória iniciam uma fase poliúrica, com diureses de 300 a $500 \mathrm{ml} /$ hora, quando ocorre melhora das condições respiratórias e hemodinâmicas. A convalescença, última fase, é lenta, podendo durar várias semanas.

O exame radiográfico de tórax dos pacientes com SPCVH mostra-se típico e, portanto, de grande importância para o diagnóstico. Exibida na Figura 4, a evolução radiológica da paciente $\mathrm{CB}$ mostra claramente o padrão radiológico da pneumopatia que ocorre na SPCVH. Acompanham o surgimento da febre e da dispnéia, no quarto dia de doença, imagens radiológicas de velamento pulmonar bilateral intersticial e que vão se tornando mistos, com infiltração alveolar. Concomitante com a agravamento da insuficiência respiratória, o velamento pulmonar misto torna-se progressivamente confluente e mais denso acometendo praticamente todos os campos pulmonares. Nessa fase, medidas terapêuticas de oxigenação, como intubação e ventilação mecânica, são necessárias. Após aproximadamente 3 dias, o quadro radiológico começa a mostrar sinais de melhora e esta remissão costuma ser progressiva. No caso da paciente CB, 2 semanas após o aparecimento dos sintomas, a remissão dos velamentos foi quase completa mantendo-se no último exame, ainda, infiltrado reticular nas bases pulmonares. Dois dos pacientes estudados apresentaram derrames pleurais, com pequeno e médio volume, associado ao quadro. Estes achados radiológicos são compatíveis com o observado em outros estudos 251722 .

O exame anátomo-patológico dos pacientes JAS e FVL, divulgado em publicação anterior ${ }^{5}$, mostrou edema alveolar difuso, membranas hialinas e infiltrado intersticial linfocitário. O estado preservado em que se encontrou as células endoteliais nos pulmões, associado à hemoconcentração e à presença, em alguns casos, de derrames pleurais, sugere que a SPCVH manifeste-se com extravasamento de líquidos dos capilares para interstício e alvéolos. Também, encontrou-se células do tipo imunoblasto nos espaços portais hepáticos e em baço. Presença de partículas virais e antígenos de Hantavirus é descrita nas células endoteliais de seres humanos infectados, bem como em roedores, ao nível dos pulmões, mas também no endotélio renal, cardíaco, hepático, esplênico e tecido adiposo ${ }^{813}$. Sabe-se que Hantavirus americanos utilizam $\beta 3$ integrinas como receptores para infectar as células 6 . Estas proteínas compõem as tightjunctions que unem as células endoteliais e fecham a barreira alvéolo-capilar. Provavelmente, em conseqüência da infecção viral do endotélio capilar, ocorreria a síndrome de extravasamento de líquidos. As plaquetas, que também possuem $\beta 3$ integrinas em membrana, são infectadas por Hantavirus americanos, ocorrendo trombocitopenia e redução da adesividade plaquetária, o que explica, em parte, fenômenos hemorrágicos que ocorrem nesses pacientes ${ }^{6}$.

Com base na fisiopatologia e na doença apresentada pelos 8 casos estudados, que tiveram taquicardia, hipotensão e retenção nitrogenada associada à dispnéia, inundação pulmonar e hipóxia, decidiu-se acrescentar ao nome síndrome pulmonar a palavra cardiovascular visando retratar melhor o que é observado nestes pacientes. Também, com base nos dados acima citados e considerando que o diagnóstico da SPCVH em sua fase prodrômica é muito difícil, já que se confundem as manifestações clínicas com as de outras viroses como a gripe, o dengue, etc, criou-se o organograma mostrado na Figura 5, para orientar o diagnóstico de casos suspeitos da hantavirose, levando em conta a fase em que já existe acometimento pulmonar. Indivíduos previamente saudáveis e com SPCVH, apresentam-se comumente ao sistema de saúde com febre e dispnéia. Nesses casos, uma radiografia de tórax deve ser realizada com urgência. O achado ao exame radiológico de infiltrado pulmonar bilateral, com padrão intersticial ou misto, acrescido de hemoconcentração e plaquetopenia no hemograma, completam a definição do caso provável de SPCVH. Fazem diagnóstico diferencial com esta síndrome as septicemias ressaltando-se as estafilocócicas, as pneumonias por outros vírus, por micoplasma e clamidia especialmente a $C$. psitacci e principalmente, a pneumocistose quando ocorre como primeira manifestação da AIDS em indivíduo previamente saudável. Entretanto, o achado de hemoconcentração concomitante a plaquetopenia não é freqüente nestes casos e sim na SPCVH. Nos pacientes com provável SPCVH devem ser imediatamente implementados cuidados de terapia intensiva.

As recomendações para o tratamento da SPCVH, com base nos surtos ocorridos na América do Norte, foram aplicadas, de forma total ou em parte, na maioria dos tratamentos dos pacientes analisados no presente estudo. Essas recomendações incluem cuidados precoces de terapia intensiva, monitoração cuidadosa da oxigenação, do balanço de fluidos, da pressão arterial e ventilação mecânica precoce ${ }^{21722}$. Inicialmente, devese oxigenar o paciente com cânula nasal ou máscara facial. Comumente, o edema intersticial progride com extravasamento de líquidos e inundação pulmonar. Nestes casos, deve-se entubar e sedar o paciente iniciando ventilação mecânica evitando distensão alveolar excessiva (ventilar com volume corrente de 6 a $8 \mathrm{ml} / \mathrm{kg}$ ). Também, durante a ventilação, deve-se evitar colapsos e reexpansões alveolares repetidas (manter pressão expiratória final positiva de 5 a $10 \mathrm{~cm} / \mathrm{H}_{2} \mathrm{O}$ ). Concomitante à ventilação, deve-se implantar no paciente catéter venoso para infusão de líquidos, de drogas e para medida da pressão venosa central (PVC). Para tratar a 
hipotensão, deve-se infundir líquidos, utilizando-se metade a $2 / 3$ de cristalóides e a outra parte de soluções coloidais. Também, deve-se utilizar drogas inotrópicas (dopamina e dobutamina) visando a melhorar o débito cardíaco e a equacionar a resistência vascular periférica desses pacientes hipotensos. Considerando-se que a barreira capilar-alvéolo se encontra patologicamente pérvia nos pacientes com SPCVH, é fundamental que a infusão de líquidos seja criteriosa e resulte em mínimo agravamento do edema pulmonar. Portanto, a infusão de líquidos deve estar condicionada ao aparecimento de edema pulmonar e de elevação da PVC acima de $12 \mathrm{~cm}$ de $\mathrm{H}_{2} \mathrm{O}$. O uso de corticosteróides não se mostrou útil no tratamento desses pacientes ${ }^{22}$. A droga antiviral ribavirina não mudou a evolução de casos de SPCVH tratados, embora tenha atuação comprovada em outra hantavirose, a febre hemorrágica com síndrome renal ${ }^{2021}$. Finalmente, recomenda-se como medida heróica, em casos de insuficiência respiratória extremamente grave, a oxigenação extracorpórea ${ }^{22}$.

Uma análise do tratamento a que foram submetidos os 8 casos de SPCVH, conforme os dados da Tabela 2, não mostra diferenças evidentes entre o que foi efetuado com os casos fatais (JAS, FVL, AGS e DLM) e os sobreviventes (VSS, CB, GSP, AJM). Não se observou correlação entre precocidade da internação ou da suposição diagnóstica de hantavirose e sobrevida. Entretanto, os pacientes falecidos JAS e DLM chegaram ao hospital em parada ou após parada cardiorespiratória, fazendo supor que, embora tenham sido reanimados, apresentaramse para tratamento em fase muito avançada e dificilmente recuperável da doença. Também, a suspeita de SPCVH para o paciente JAS foi retrospectiva, ocorrendo após o óbito. Ainda, dois casos fatais tiveram os níveis mais baixos de saturação de oxigênio o que sugere uma gravidade maior da insuficiência respiratória por eles apresentada. A presença de choque foi observada em 6 dos 8 pacientes estudados e não teve correlação com óbito. A oxigenação, na grande maioria dos casos ocorrendo no primeiro dia de internação e utilizando ventilação mecânica, não teve correlação com sobrevida. O tratamento da hipotensão sob controle de PVC, o volume de líquido infundido nas primeiras $48 \mathrm{~h}$, o uso de aminas vasoativas e o uso de corticosteróides, também, não mostraram correlação com sobrevida. Entretanto, o paciente DLM recebeu, para tratamento do choque, infusão rápida de $3 \mathrm{~L}$ de solução cristalóide nas 3h que precederam o óbito. É possível que este líquido rapidamente infundido tenha agravado o processo de extravasamento para o interstício pulmonar e alvéolos piorando a insuficiência respiratória. Em todos os casos, o diagnóstico sorológico confirmatório de hantavirose só foi informado durante a convalescença ou após o óbito destes pacientes. Desconhecendo-se a etiologia da grave síndrome infecciosa, todos os pacientes fizeram uso de antimicrobianos visando a atuar sobre bactérias que incluíam Staphylococcus aureus, Mycoplasma sp, Legionella sp e fungos como Pneumocystis carinii. Observa-se que todos os sobreviventes fizeram uso de claritromicina, o que não ocorreu com nenhum dos casos fatais. Entretanto, sendo esta uma pequena casuística e desconhecendo qualquer atividade antiviral da claritromicina, é provável que esta observação seja apenas uma coincidência. Finalmente, o paciente GSP, de 54 anos e que havia sofrido parada cardiorrespiratória prévia, sofreu morte súbita no $4^{\circ}$ dia após a internação, quando se encontrava iniciando a convalescença. É possível que este óbito tenha se devido à complicações de outra ordem. Os 4 pacientes que sobreviveram à SPCVH tiveram cura completa não tendo sido observadas seqüelas pulmonares, renais ou cardiovasculares.

Considerando que a SPCVH é doença grave, com alta mortalidade e que a transmissão interpessoal de Hantavirus ocorre, inclusive acometendo o pessoal médico, embora tenha sido observada apenas no surto argentino pelo vírus Andes, em 1996, recomenda-se que sejam tomadas medidas de isolamento em quarto privativo dos casos com esta suspeita diagnóstica e que a equipe médica cuidando destes pacientes tome precauções universais e respiratórias utilizando luvas, avental, óculos e máscaras de tipo N95 ${ }^{515}$. Idealmente, estas medidas devem ser tomadas até o desaparecimento do quadro respiratório e da febre.

A mortalidade de $50 \%$ observada entre os 8 casos de SPCVHé elevada e igual à ocorrida em surtos argentinos pelo vírus Andes ${ }^{17}$. Quanto aos surtos ocasionados pelo vírus Sin Nombre na América do Norte, a mortalidade que era superior a $50 \%$ em 1993 , caiu para $40 \%$ em $1994-$ 1996 e em 1997, de 20 casos notificados, apenas 20\% morreram ${ }^{17}$. Tal fato pode ser atribuído ao incremento das informações sobre esta hantavirose levando ao diagnóstico progressivo de casos com menor gravidade e, também, a um tratamento mais eficaz dos pacientes com SPCVH.

A análise dos 8 pacientes com SPCVH, as informações sobre roedores silvestres e os dados da literatura sobre esta hantavirose permitem as seguintes observações e sugestões:

- A SPCVH está relacionada ao meio rural e ao contato com roedores silvestres tendo provavelmente uma sazonalidade com predomínio de ocorrências nos meses de maio e junho.

- A SPCVH é doença grave que leva à insuficiência respiratória, choque e óbito.

- A terapia de suporte ventilatório e cardiovascular deve ser precocemente instituída, preferencialmente em unidades de terapia intensiva.

- Precauções universais e respiratórias de isolamento devem ser tomadas pelo pessoal médico no cuidado com casos suspeitos de SPCVH.

- A presença de edema pulmonar exige que a entubação traqueal e a ventilação mecânica sejam precocemente implementadas.

- Apesar da maioria dos pacientes apresentar-se em choque, deve-se ter cuidados com a infusão de líquidos, 
considerando-se a PVC e sinais clínicos, para que não se agrave o edema pulmonar.

- A mortalidade de $50 \%$ observada entre os 8 casos de SPCVH é elevada e provavelmente, deveu-se à gravidade própria da doença bem como a diferentes fatores, como: comparecimento tardio a hospital com recursos de terapia intensiva, quando o quadro de insuficiência respiratória era gravíssimo e irreversível; pacientes com seqüelas conseqüentes à parada cardiorespiratória e ocorrência de infusão rápida de líquidos pela via parenteral, sem cuidados adequados com relação ao agravamento da pneumopatia.

- Há necessidade de incrementar as informações sobre a SPCVH aos profissionais de saúde, considerando que muitos casos, provavelmente, passam desapercebidos e com outros diagnósticos.

Diagnóstico laboratorial de hantavirose acessível e rápido precisa ser implementado. Para tanto, faz-se necessário o estabelecimento de pesquisas para desenvolver métodos laboratoriais diagnósticos sensíveis e confiáveis, bem como disponibilizar reagentes e insumos.

- O controle desta hantavirose exige o envolvimento de múltiplos profissionais visando a conhecer a história natural, a biologia do reservatório e do vírus, a doença e a promover a cura dos casos, bem como a implementar medidas preventivas ${ }^{120}$.

\section{AGRADECIMENTOS}

Os autores agradecem aos Professores da FMRP-USP, Clóvis Simão, pela revisão de exames radiológicos e João Carlos da Costa, pela revisão do manuscrito e sugestões. Agradecem, também, ao estudante de medicina da Universidade do Texas nos Estados Unidos, Robert Ryan Holmes pelo auxílio no diagnóstico sorológico dos casos de hantavirose e ao Dr. Thomas. G. Ksiazek, do Centro de Controle de Doenças de Atlanta nos Estados Unidos, pelo fornecimento de reagentes para os testes sorológicos.

\section{REFERÊNCIAS BIBLIOGRÁFICAS}

1. Centers for Disease Control and Prevention. Hantavirus infection recommendations for risk reduction. Morbidity and Mortality Weekly Report 11:1-12, 1993.

2. Duchin JS, Koster FT, Peters CJ, Simpson GL, Tempest B, Zaki SR, Ksiazek TG, Rollin PE, Nichol S, Umland ET, Moolenaar RL, Reef SE, Nolte KB, Gallaher MM, Butler JC, Breiman RF. Hantavirus pulmonary syndrome: a clinical description of 17 patients with a newly recognized disease. New England Journal of Medicine 330:949-955, 1994

3. Engelthaler DM, Mosley DG, Cheek JE, Levy CE, Komatsu KK, Ettestad P, Davis T, Tanda DT, Miller L, Frampton JW, Porter R, Bryan RT. Climatic and environmental patterns associated with hantavirus pulmonary syndrome, Four Corners Region, United States. Emerging Infectious Diseases 5:87-94, 1999.

4. Ferreira LT, Pereira LE, Suzuki A. Hantavirus Pulmonary Syndrome in São Paulo and Mato Grosso States, Brazil. Virus Reviews \& Research 3 (Suppl 1):43, 1998.

5. Figueiredo LT, Moreli ML, Almeida VS, Félix PR, Bruno JC, Ferreira IB, Mançano FD. Hantavirus pulmonary syndrome in Guariba, SP, Brazil. Report of 2 cases. Revista do Instituto de Medicina Tropical São Paulo 41:131-137, 1999.

6. Gravilovskaya IN, LaMonica R, Mackow ER. PH induced changes in hantavirus glycoproteins abolish interactions with b3 integrins but are required for viral entry through acidified endosomes. Scientific Programs and Abstracts of the $18^{\text {th }}$ Annual Meeting of the American Society for Virology, Amherst, p.129, 1999.

7. Gravilovskaya IN, Shepley M, Shaw R, Ginsberg MH, Mackow ER. B3 integrins mediate the cellular entry of hantaviruses that cause respiratory failure. Proceedings of the National Academy of Sciences of the United States 95:7074-7079, 1998.

8. Green W, Feddersen R, Yousef O, Behr M, Smith K, Nestler J, Jenison S, Yamada T, Hjelle B. Tissue distribution of hantavirus antigen in naturally infected humans and deer mice. Journal Infectious Diseases 177:1696-1700, 1998.
9. Iversson LB. Doença humana por hantavirus. In: Veronesi R, Focaccia R (eds) Tratado de infectologia, São Paulo, Atheneu, 219-228, 1996.

10. Iversson LB, Rosa AP, Rosa MD, Lomar AV, Sasaki GM, LeDuc JW. Infecção humana por hantavirus nas regiões sul e sudeste do Brasil. Revista da Associação Médica Brasileira 40:85-92, 1994.

11. Jenison S, Yamada T, Morris C, Anderson B, Torrez-Martinez N, Keller N, Hgelle B. Characterization of human antibody responses to Four Corners hantavirus pulmonary syndrome. Journal of Virology 68:3000-3006, 1994.

12. Johnson AM, Bowen MD, Ksiazek TG, Williams RJ, Bryan RT, Mills JN, Peters CJ, Nichol ST. Laguna Negra virus associated with HPS in western Paraguay and Bolivia. Virology 238:115-127, 1997.

13. Kirkendoll-Ahern H, Botten JW, Kusewitt D. Kinetics and tissue distribution of acute sin nombre virus infection in the deer mouse. In: Scientific Programs and Abstracts of the $18^{\text {th }}$ Annual Meeting of the American Society for Virology, Amherst, 130, 1999.

14. LeDuc JW, Smith GA, Pinheiro FP, Vasconcelos PF, Rosa ES, Maiztegui JI. Isolation of a Hantaan-related virus from Brazilian rats and serologic evidence of its widespread distribution in South America. American Journal of Tropical Medicine and Hygiene 34:810-815, 1985.

15. Levis S, Morzunov SP, Rowe JE, Enria d, Pini N, Calderon G, Sabattini M, St.Jeor SC. Genetic diversity and epidemiology of Hantaviruses in Argentina. Journal of Infectious Diseases 177:529538, 1998.

16. Pereira LE. A atual situação dos hantavirus. Vetores \& Pragas 4:28-30, 1999.

17. Peters CJ. HPS in the Americas. In: Scheld WM, Craig WA Hughes JM (eds) Emerging Infections 2, Washington DC, ASM Press, p.17-64. 1998. 
18. Schmaljohn CS. Bunyaviridae: the viruses and their replication. In: Fields B, Knipe DM, Howley PM (eds) Fundamental Virology, Philadelphia Lipincott-Raven, p. 649-673, 1996.

19. Schmaljohn CS, Hjelle B. Hantaviruses: a global disease problem. Emerging Infectious Diseases 3:95-104, 1997.

20. Shope RE. A midcourse assessment of hantavirus pulmonary syndrome. Emerging Infectious Diseases 5:172-174, 1999.

21. Silva MV. Hantavirus pulmonary syndrome: report of the first three cases in São Paulo, Brazil. Revista do Instituto de Medicina Tropical São Paulo 39:231-234, 1998.

22. Simpson SQ. Hantavirus pulmonary syndrome. Heart \& Lung 27:51-57, 1998.

23. Toledo Filho DV. Composição florística e estrutura fitossociológica da vegetação do cerrado no Município de Luis Antônio (SP).
Dissertação de Mestrado, Instituto de Biologia/Universidade de Campinas, Campinas, SP, 1984.

24. Vasconcelos MJ, Pedroso de Lima VC, Iversson LB. Hantavirus pulmonary syndrome in the rural area of Juquitiba, metropolitan area of São Paulo, Brazil. Revista do Instituto de Medicina Tropical São Paulo 39:237-238, 1997.

25. Wells RM, Estani SS, Yadon ZE. An unusual outbreak in southern Argentina: person-to-person transmission? Emerging Infectious Diseases 3:171-174, 1997.

26. Xiao SY, Leduc JW, Chu YK, Schmaljohn CS. Phylogenetic analyses of virus isolates in the genus Hantavirus, family Bunyaviridae. Virology 198:205-217, 1994.

27. Zhao X, Hay J. The evolution of hantaviruses. Immunological Investigations 26:191-197, 1997. 